\title{
Meet the ACRL staff
}

Although many of you have talked to ACRL staff members on the phone, very few of you have had a chance to meet them in person. ACRL has 12.95 ALAapproved FTE positions at headquarters. On these pages we are presenting current ACRL staff with brief comments about their cluties. We're also including two of ACRL's Cboice staff. Take a minute to familiarize yourself with the people behind the scenes at ACRL. We look forward to hearing from you.

JACK BRIODY, program as-
sistant, manages the ACRL
Awards program, oversees
the ACRL appointments and
nominations, updates the $A L A$
Handbook, maintains the di-
vision roster and donor
records, and assists the asso-
ciate executive director for
special programs. Phone:
(312) 280-2516; e-mail:
jack.briody@ala.org.

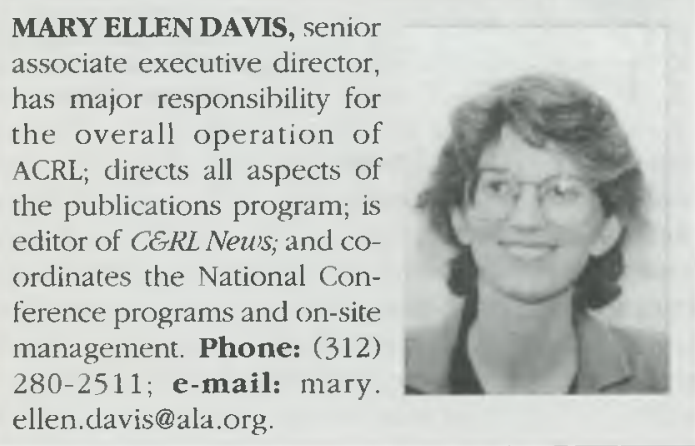

FRANCINE GRAF, managing editor of Choice, manages all editorial aspects of the magazine, reviews-oncards, and electronic databases; coordinates the work of Choice's editorial staff; plans the editorial calendar; and handles Choice's business and economics sections. Phone: (860) 347-6933; e-mail: frangraf@delphi.com.

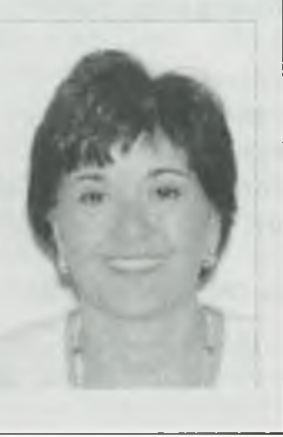

DARLENA DAVIS, administrative secretary, provides support for National Conference planning and activities; maintains publications files and records; and provides secretarial support for publications and journals. Phone: (312) 280-2519; e-mail: dariena. davis@ala.org.

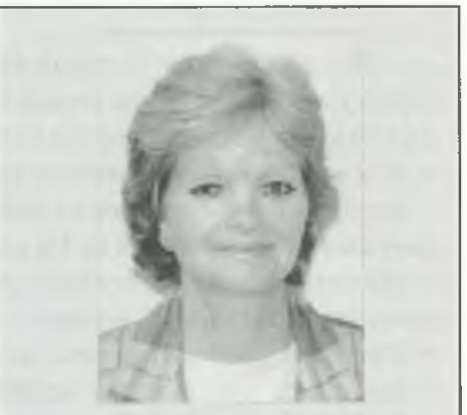

NOREEN HALE, associate executive director for special programs and advancement, is the contact for selected committees; manages membership promotion and retention, special programs, institutes, and forums; and provides advisory services. Phone: (312) 280-2510;e-mail: noreen.hale@ala.org. 


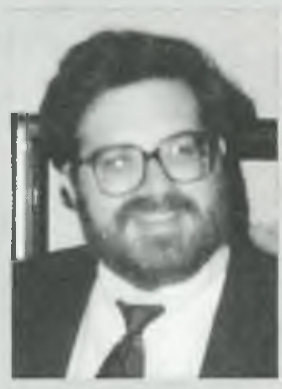

JACK HELBIG, classified ad manager for CERL News, manages all aspects of the Neus' classified advertising, including promotion, order taking, page layout, customer service, CERL NewsNet, and billing. Phone: (312) 280-2513; fax: (312) 2807663; e-mail: jack.helbig@ ala.org

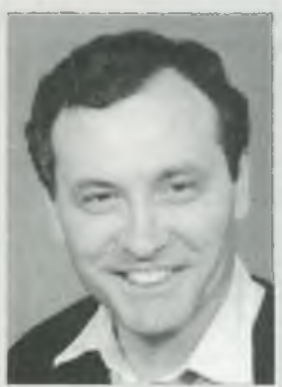

IRVING ROCKWOOD, editor and publisher of Choice, directs all aspects of the Choice publishing program including the magazine, reviews-on-cards, electronic databases, and new products. He is responsible for the overall administration of the Choice office. Phone: (860) 347-6933; e-mail: irv_rockwood@delphi.com.

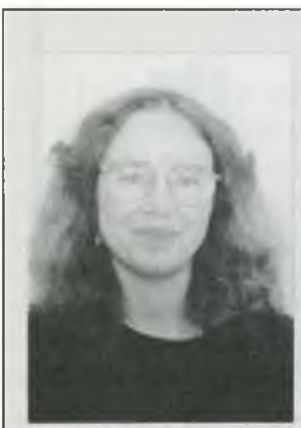

PAM SPIEGEL, production editor of ACRL journals, handles page layout, copyediting, and general production of CERL Neus, $C E R L$, and $R B M L$, and writes columns and other pieces for CERL News. Phone: (312) 280-2524; e-mail: pam.spiegel@ala.org.

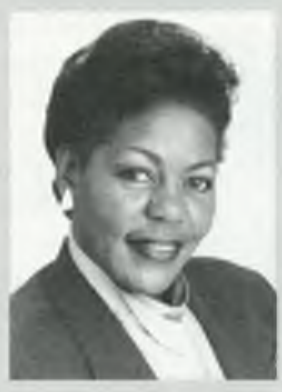

ALTHEA JENKINS, executive director, is responsible for planning, executing, and implementing all ACRL programs including Choice, under the general direction of the ACRL Board of Directors. She also is responsible for the overall administration and control of activities of ACRL's offices and employees as authorized by the ALA Executive Board through the ALA executive director. Phone: (312) 280-3248; e-mail: althea.jenkins@ala.org. 

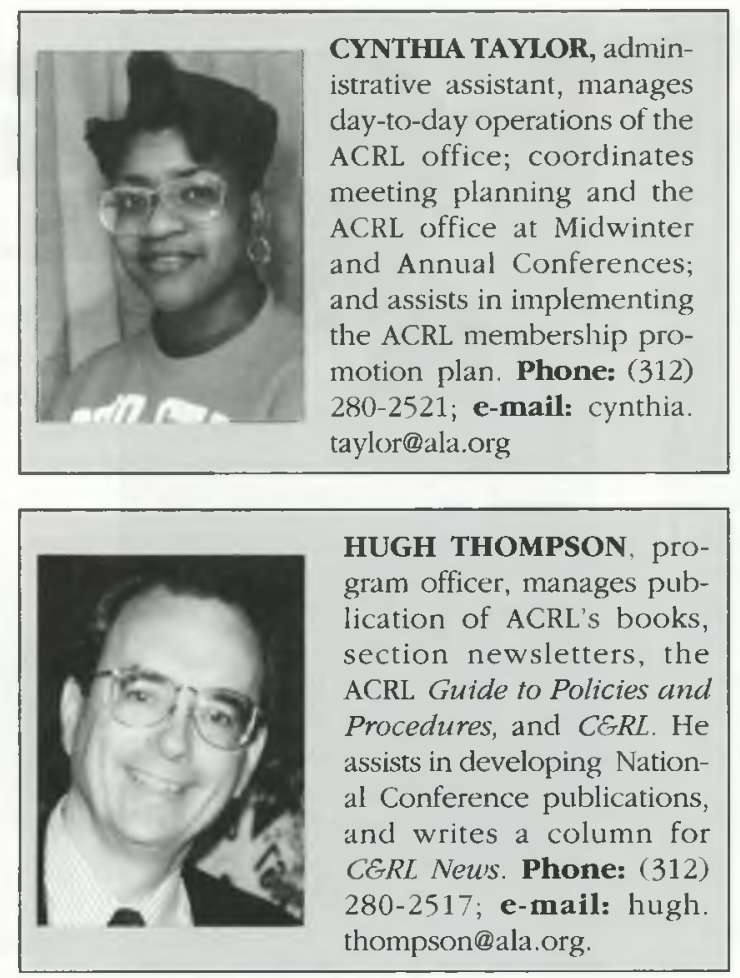

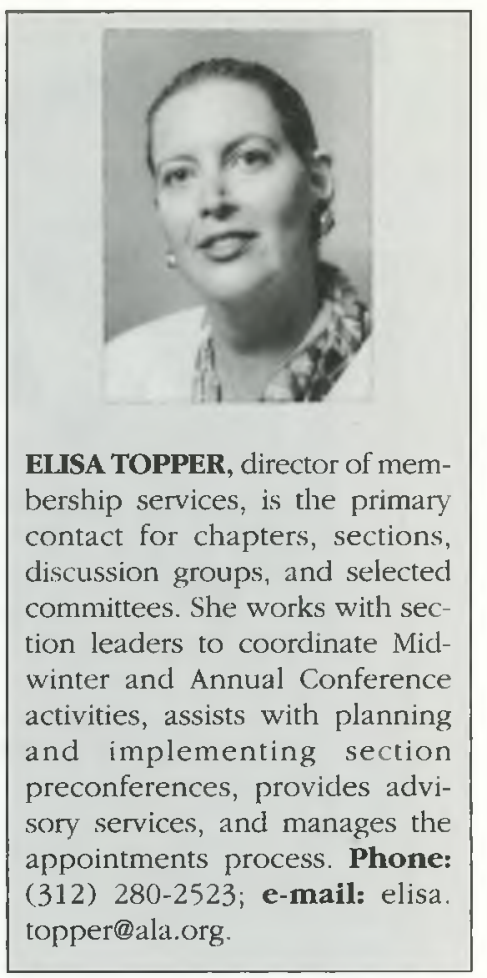

\section{Use INTERNET to}

\section{UnCover...}

\section{UnCover}

6 million articles from 20,000 multidisciplinary periodicals delivered by fax in 24 hours or less

UnCover
Reveal
Electronic TOC
service with
user profiling

UnCover Complete

Pre-1989 journals can be ordered online

\section{UnCover SOS}

Order articles by fax, phone, e-mail or post from UnCover's Single Order Source service

The UnCover Company

E-mail: uncover@carl.org

380I East Florida Avenue, Suite 200 a Denver, CO 80210, USA

Phone: I-800-787-7979 ב Fax: 303-758-5946

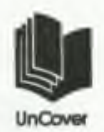

Readmore, Inc.

22 Cortlandt Street

New York, NY 10007

Phone: $|-800-22|-3306$

\section{...Articles}

UnCover is a service of Readmore, Inc. 